\title{
The effects on children of depressed mothers' remission and relapse over 9 months
}

\author{
M. M. Weissman ${ }^{1,2,3,{ }^{*}, \dagger}$, P. Wickramaratne ${ }^{1,3, \dagger}$, D. J. Pilowsky ${ }^{1,2,3}$, E. Poh ${ }^{1}$, M. Hernandez ${ }^{1}$, \\ L. A. Batten ${ }^{4,5}$, M. F. Flament ${ }^{4}$, J. W. Stewart ${ }^{1,3}$, and P. Blier ${ }^{4}$ \\ ${ }^{1}$ Division of Epidemiology, New York State Psychiatric Institute, New York, NY, USA \\ ${ }^{2}$ Department of Epidemiology at the Mailman School of Public Health at Columbia University, \\ New York, NY, USA \\ ${ }^{3}$ Department of Psychiatry, College of Physicians and Surgeons, Columbia University, New York, \\ NY, USA \\ ${ }^{4}$ University of Ottawa Institute of Mental Health Research, Ottawa, ON, Canada \\ ${ }^{5}$ Carleton University, Ottawa, ON, Canada
}

\begin{abstract}
Background-The high rate of depression among children of depressed mothers is well known. Suggestions that improvement in maternal acute depression has a positive effect on the child have emerged. However, data on the mechanisms of change have been sparse. The aim was to understand how remission and relapse in the mother might explain the changes in the child's outcome.
\end{abstract}

\begin{abstract}
Method-Participants were 76 depressed mothers who entered into a medication clinical trial for depression and 135 of their eligible offspring ages 7-17 years. The mothers and children were assessed at baseline and periodically over 9 months by independent teams to understand the relationship between changes in children's symptoms and functioning and maternal remission or relapse. The main outcome measures were, for mothers, the Hamilton Depression Rating Scale (HAMD), the Social Adjustment Scale (SAS) and the Parental Bonding Instrument (PBI) and, for children, the Children's Depression Inventory (CDI), the Columbia Impairment Scale (CIS), the Multidimensional Anxiety Scale for Children (MASC) and the Children's Global Assessment Scale (CGAS).
\end{abstract}

Results-Maternal remission was associated with a decrease in the child's depressive symptoms. The mother's subsequent relapse was associated with an increase in the child's symptoms over 9 months. The effect of maternal remission on the child's improvement was partially explained by an improvement in the mother's parenting, particularly the change in the mother's ability to listen

\footnotetext{
(C) 2014 Cambridge University Press

*Address for correspondence: M. M. Weissman, Ph.D., Diane Goldman Kemper Family Professor of Epidemiology in Psychiatry, College of Physicians \& Surgeons, Mailman School of Public Health, Columbia University, Chief, Division of Epidemiology, New York State Psychiatric Institute, 1051 Riverside Drive - Unit 24, New York, NY 10032, USA. (mmw3@columbia.edu).

These authors contributed equally as joint first authors.

Supplementary material

For supplementary material accompanying this paper visit http://dx.doi.org/10.1017/S003329171400021X.
} 
and talk to her child, but also reflected in her improvement in parental bonding. These findings could not be explained by the child's treatment.

Conclusions-A depressed mother's remission is associated with her improvement in parenting and a decrease in her child's symptoms. Her relapse is associated with an increase in her child's symptoms.

\section{Keywords}

Child depression; maternal depression; parental functioning; remission

\section{Background}

The high rate of depression and anxiety among children of depressed mothers has implications for early intervention (Lieb et al. 2002; Weissman et al. 2006a; Beardslee et al. 2011). Depression is a complex disorder and environmental stress probably triggers episodes. Having an acutely depressed parent is a stressful experience for a child. Suggestions that improvement in maternal depression has a positive effect on the children have emerged. However, data on what changes in the relationship based on independent assessments of mothers and children have been sparse (Gunlicks \& Weissman, 2008).

We have shown in the Sequenced Treatment Alternative to Depression (STAR*D) study, a large effectiveness trial designed to determine how to achieve remission for depression in adults, that remission of maternal depression after 3 months of medication treatment was significantly associated with a reduction in children's depressive symptoms (Weissman $e t$ al. 2006a). These results were sustained in the children 1 year after maternal remission (Wickramaratne et al. 2011). A statistically significant decrease in symptoms was seen in the children of mothers who remitted early (within the first 3 months) or late (over the 1year follow-up), compared to the children of mothers who did not remit (Pilowsky et al. 2008). Garber et al. (2011) also independently showed similar relationships between depressed mothers and a reduction in their children's depressive symptoms. As STAR*D was a pragmatic trial, to mimic clinical practice there were sparse assessments of both the children and the mothers. Here we describe the 9-month results of a new study examining the relationship between maternal remission and relapse and child outcome.

\section{Method}

Children of depressed mothers participating in a randomized, double-blind clinical trial testing the effects of escitalopram, bupropion, or their combination for 12 weeks, followed by an open trial for an additional 24 weeks (total 9 months) (Stewart et al. 2013) were independently assessed. Adult study participants were out-patients aged 18-65 years, with non-psychotic major depressive disorder (MDD), and without a lifetime history of bipolar disorder, schizophrenia, schizo-affective disorder, or a current substance use disorder. Patients with current medical and psychiatric conditions, except those already, were included unless a medical condition contraindicated the use of the medications. Parents were considered eligible for the Child Study if they participated in the adult treatment study, had at least one child aged 7-17 years who was living at least half of the time with the treated 
parent, and with no developmental disability that would preclude participation. All willing eligible parents and children were enrolled. Only mothers are included in these analyses. Treatment was not provided to the children but they were not excluded if they were in treatment. Referrals were given if needed or requested. The protocol was approved by the institutional review boards and took place in New York City, USA and Ottawa, Canada.

\section{Adult Study}

The mothers' initial diagnoses were established by the Structured Clinical Interview for DSM-IV Axis I Disorders, Patient Edition (SCID-I/P; First et al. 2008). The severity of depressive symptoms was estimated by the 17-item Hamilton Depression Rating Scale (HAMD-17; Hamilton, 1967), ranking symptoms from 0 (not present) to 4 (extreme), or 0 to 2 for symptoms that are difficult to quantify reliably. Scores range from 0 to 50 . A score of $\checkmark 7$ was considered to represent remission; $\geq 23$ severe (Endicott et al. 1981). To describe the outcome in these analyses, remission was defined as a HAMD-17 score $\leq 7$, and $<14$ for the remainder of the study; relapse as a HAMD-17 score $\geq 14$ after obtaining remission status (HAMD-17 57); and non-remission as a HAMD-17 score > 7 for the whole duration of the study or until drop-out.

The Social Adjustment Scale - Self-Report (SAS-SR) assessed performance in work, social and leisure activities, relationships with extended family, role as a marital partner, parental role, and financial status (Weissman et al. 1978; Gameroff et al. 2012). The parenting questions involved interest in child activities, ability to talk and listen to your child, getting along with your child, and feeling affection towards your child. Answers were on a fivepoint scale with high scores indicating more impairment. The mother's perception of their own parenting was assessed using the Parental Bonding Instrument (PBI), a self-report measure (Parker et al. 1979; Murphy et al. 2010). The two main dimensions are care and control. Mothers who scored low on caring (12 items, e.g. 'was not affectionate', 'did not seem to understand what child needed') and high on control (13 items, e.g. 'did not want child to grow up', 'tried to control everything child did') were classified as having affectionless control. The child was independently asked the same questions from the PBI as the mother.

\section{Child Study}

The Child Study assessments were conducted by an independent team who knew that participating mothers were depressed and were participating in the adult study, but did not have access to parental depression assessments or treatment status. Parents and children were assessed at baseline within 2 weeks of the initiation of parental treatment and at 4, 8, 12, 24 and 36 weeks after baseline on all clinical measures except the PBI, which was given at baseline, 3 and 9 months only. During the clinical trial, the mothers were also assessed at weeks $1,2,3$ and 10 .

Children's psychiatric disorders were established by direct separate interviews of mothers and children using the Schedule for Affective Disorders and Schizophrenia for School-Age Children - Present and Lifetime Version (K-SADS-PL; Kaufman et al. 1997). Children were interviewed first. Depressive symptoms were assessed by the Children's Depression 
Inventory (CDI), a self-report measure for children and adolescents (Kovacs, 1992; Brotman et al. 2008) covering mood, hedonic capacity, vegetative signs, self-concept and interpersonal behaviors. Each item was scored as 0 (symptom is absent), 1 (mild) or 2 (definite). The Multidimensional Anxiety Scale for Children (MASC) was used to assess four domains of anxiety symptoms: physical, social, harm avoidance, and separation (panic). Children's responses are on a four-point Likert scale in answers to the question: 'How often is the statement true for you?' (March, 1997; March et al. 1997; March \& Parker, 1999). Children's functioning was assessed by the Columbia Impairment Scale (CIS), resulting in an overall impairment score rated from 0 (no problem) to 4 (serious problem) (Bird et al. 1993). The Child Global Assessment Scale (C-GAS) is a clinician-rated overall estimate of functioning (range 0-100), with scores $>90$ indicating superior functioning and scores $<70$ indicating impaired global functioning (Shaffer et al. 1983). The children also completed the PBI regarding their perception of their mother's parenting. The assessment is described under the Adult Study.

All mental health treatment received by the child historically at baseline and during the 9 months from mothers in response to systematic questions was recorded. Mothers were asked if the child received treatment for a psychiatric condition or emotional problem during a specific time. Any affirmative answer was followed up with inquiries about details. Six interviewers with prior clinical experience with children and adolescents trained in the study assessments and monitored over the course of the study under the supervision of child psychiatrists (D.J.P. and M.F.F.) completed the child assessments. Full details of the training, monitoring and reliability of symptoms and diagnostic measures are described in Batten et al. (2012).

\section{Data analysis}

Differences in the means of continuous variables by maternal remission status for mothers' baseline characteristics were determined by using analysis of variance, and differences in the distribution of categorical variables by maternal remission status were analyzed using contingency table analysis and associated $\chi^{2}$ tests or Fisher's exact tests when counts were low. Differences in children's baseline characteristics by maternal remission status were analyzed using linear mixed models for continuous variables and logistic regression analyses in the context of the generalizing estimating equations (GEE) approach (Liang \& Zeger, 1986) to adjust for correlation between siblings. Baseline characteristics found to be significantly different were adjusted for in subsequent analyses.

Differential effects of remission status on child outcomes were investigated as follows. When the child outcome was a continuous variable, linear mixed effects regression models were fitted to the data with the child outcome variable as the dependent variable and maternal treatment status and time (study week) as independent variables, in addition to an interaction term representing remission status $x$ time. Age and sex of child, along with site, were included as covariates. Correlations between repeated measures over time, and also potential non-independence of observations between siblings, were handled by including nested random effects in the model, with subjects nested within family (Singer, 1998). When child outcomes were either binary variables (child diagnoses) or count variables (child 
symptoms), logistic regression (for binary outcomes) and Poisson regression (for outcomes that are counts) were used in the framework of the GEE approach to determine differential effects of maternal treatment on these outcomes. Repeated measures over time and nonindependence of siblings were accounted for by using an independence correlation matrix because the clusters are perfectly nested (repeated measures over time within siblings) (Berensky et al. 2000). Potential confounding variables were handled as described for continuous outcomes.

Associations of maternal remission status with change in the mother's depressive symptoms and functioning were analyzed using linear mixed effects regression analyses, which account for the nesting of time within person to test linear and curvilinear (quadratic) trends over time and their interaction with remission status. Missing covariate data were imputed using the multiple imputation procedure in SAS version 9.3 (SAS Institute Inc., USA) based on existing responses for all SAS-SR items to maximize available data to test for mediated moderation analysis of the significant remission effects on child outcomes.

For those child outcomes that showed statistically significant differences in trend parameters over time by maternal remission status, we investigated whether differential effects of changes in maternal functioning (as measured by the SAS-SR roles) over time could explain these differences by including maternal functioning variables as time-varying covariates in models with relevant child outcomes as dependent variables, and tested for main effects and/or interactions of maternal functioning over time by maternal remission status.

\section{Results}

Two hundred and forty-five subjects aged 18-65 years were recruited at two psychiatric outpatient clinics in New York City and Ottawa (Fig. 1). A total of 110 subjects had ageeligible children (7-17 years), and of these 175 eligible children, 168 agreed to participate. Eleven of the 93 subjects were fathers. These 11 fathers and their 23 children were excluded from this study because the aim was to study the effect of maternal remission on offspring, resulting in a total of 82 mothers and their 145 children who consented and received a baseline assessment. Six of these mothers did not receive treatment and along with their 10 children were excluded from the study, leaving a total of 76 mothers who entered the Adult Study and 135 children. Of the 82 mothers and 145 children who received baseline assessment, 67 mothers (82\%) and 121 children (83\%) completed the full 9-month assessments.

There were no significant differences in demographic or clinical characteristics between the 67 mothers who completed the study and the nine who dropped out; neither were there any statistically significant differences in these characteristics between 121 children who completed the study and the 14 children of mothers who dropped out (see Supplementary Table S1).

\section{Characteristics of mothers and children}

Of the mothers who received treatment, 55/76 (72.4\%) met remission criteria at or before the 9-month follow-up assessment. The average time to remission was 51.2 (S.D.=38.3) 
days. Of the 55 mothers who remitted, $21.8 \%$ (12/55) met criterion for a relapse during the 9 months. The remission status of the mothers who dropped out before study completion was based on the status at the time of drop-out. Table 1 summarizes the baseline characteristics of mothers and their children by maternal remission/relapse status. There were no significant differences on any of the maternal or child baseline demographic or clinical characteristics.

\section{Maternal remission and child outcomes over 9 months}

Changes in child outcomes were compared by maternal remission status (remitters, relapsers, non-remitters) while adjusting for child age, gender, site and sibling correlation (Table 2). During the 9-month follow-up, there was a statistically significant improvement in all outcomes (with the exception of diagnoses and child-reported symptoms on the KSADS, which only showed a trend) of children of remitting mothers, as reflected in their associated $\beta$ coefficients presented in Table 2 . By contrast, children of relapsing mothers and children of non-remitting mothers showed no statistically significant improvements over this same period of time on any of the child outcomes. Formal tests of interaction found that there were statistically significant differences between mothers' remission status for the following outcomes: CGAS, CDI, MASC Social Anxiety and MASC Total. Pairwise comparisons for these outcomes showed that there were significant differences in children of mothers who remitted compared to children of non-remitting mothers on improvement in CDI, MASC Social Anxiety score and MASC Total score; significant differences in children of remitters versus children of relapsers in rate of change in CGAS; and a trend for differences in rates of improvement for children of remitting mothers compared to children of relapsing mothers for MASC Social Anxiety and MASC Total scores.

\section{Relationship between maternal remission and maternal functioning over 9 months}

There were significant differences in the rate of change in maternal functioning (as measured by the SAS-SR) by maternal remission status in all domains (Table $3 a$ ). However, the patterns of differences varied by domain. Although there was a statistically significant improvement in time for overall functioning in all categories, the rate of improvement was significantly better in mothers who remitted than in those who relapsed or did not remit. Similar patterns were observed for the family and social and leisure roles, although for these domains the rate of improvement for non-remitting mothers was only at trend level. In the roles of work and finance, only remitting mothers showed significant improvement.

Maternal functioning showed significant improvement for each individual item and the total score only in remitted mothers. No significant improvement over time was observed on any of these items for mothers who relapsed or those who did not remit. Figure 2 shows graphically the overall parental functioning by maternal remission studies. Rates of change in parenting as measured by the PBI mother's report (Table $3 b$ ) showed statistically significant differences on the overprotection measure by maternal remission status, with remitting mothers reporting a significant improvement on the overprotection measure over time, and non-remitting mothers showing a trend for improvement. There was no significant improvement reported by relapsing mothers. PBI child reports on overprotection showed 
similar patterns although formal tests of interaction did not reach the level of statistical significance.

\section{Relationships between maternal functioning/bonding and the effect of maternal remission status on child symptoms}

Table 4 shows the results of the analyses to determine whether changes in maternal social functioning or bonding over time explained the observed effect of maternal remission status on the child. The change in SAS-SR Total score partially explained the effects of maternal remission status for the child's MASC Social and MASC Total scores; for these scores, there were significant differences in linear change slopes between children of remitting mothers and children of non-remitting mothers only. Therefore, we focused our analysis on this pairwise comparison. The significant differential change over time in MASC Social and MASC Total scores by maternal remission status was decreased with the inclusion of SASSR Total score (as a time-dependent covariate). In addition, the SAS-SR Total score was found to be a predictor of child's MASC Social and MASC Total scores. Further investigation revealed that change in the SAS-SR Parental Functioning score also partially explained the effects of maternal remission status on MASC Social and Total scores in a similar manner.

The differential effects of parental functioning item no. 2 (i.e. 'able to listen to and talk to my child') by maternal remission status partially explained the effect of maternal remission status on change over time in the child's CDI scores, along with MASC Social and MASC Total scores. Similar to the MASC Social and MASC Total scores, for CDI scores there were also significant differences in linear change slopes between children of remitting mothers and children of non-remitting mothers only. As a result we focused our analysis on this pairwise comparison. The statistically significant interaction between change in CDI score over time and maternal remission status (denoted by the $p$ value corresponding to the two-way interaction term week $\times$ remission status; $\beta=-0.08, p=0.0213$ ) decreased with the inclusion of the main effect of the average parental functioning item no. 2 and its interaction with maternal remission status ( $\beta=-0.06, p=0.0952)$. In addition, the interaction between average parental functioning and maternal remission status was statistically significant, implying that the association between parental functioning scores and child CDI symptoms varied with maternal remission status $(p=0.038)$. For MASC Social and MASC Total scores, the significant differential change in these scores over time by maternal remission status was decreased by the inclusion of parental functioning item no. 2 as a time-dependent covariate. In addition, parental functioning was found to be a predictor of MASC Social and MASC Total scores (Table 4).

We also found that mother's report of overprotection (assessed by the PBI) showed similar results to the parental functioning item no. 2, with the relationship between the PBI overprotection score and MASC Social score partially explaining the effects of maternal remission status (lower portion of Table 4), although these findings were not as strong as that seen for the SAS-SR parenting item no. 2, probably because the PBI assessments were made at fewer time points than the SAS-SR. Furthermore, the PBI has been shown to be stable over time and not strongly affected by current symptoms (Murphy et al. 2010). 


\section{Treatment received by children over 9 months}

We looked at treatment received by the children over the 9 months to see if it might explain the differential effects of mother's remission status. There was no difference in the number of children receiving some mental health treatment by mother's final remission status either at baseline (remission: $22.4 \%$; relapse: $16.7 \%$; no remission: $38.2 \%$ ) or during the course of the 9 months (19.7, 16.7 and 26.5\% respectively). Two children were hospitalized over the 9 months, one child a remitter and one of a non-remitter.

\section{Discussion}

The increased rate of depression in offspring of depressed mothers is one of the best replicated findings in psychiatry. This study, along with several others with different design, clearly shows the relationship between the mother's acute depressive symptoms and the child's current clinical status (Gunlicks \& Weissman, 2008). Our study adds to the findings by showing that maternal remission is associated with an improvement in children's depressive symptoms whereas maternal relapse after remission is associated with an increase in children's symptoms. The effect of maternal remission status on the child is partially explained by the mother's perceived improvement in parenting. Of interest, not all other domains of maternal social functioning improved at the same rates. These findings on maternal remission and child's improvement at 9 months are similar to our STAR*D findings at 1 year in that we found a continuing decrease in the child's symptoms over time (Pilowsky et al. 2008). We also found that most of the maternal remission occurred within the first 3 months after initiation of treatment. In STAR*D, the benefit for children was greater when mothers remitted early; however, children of late remitting mothers also experienced a statistically significant decrease in symptoms. In the current study, we could not compare early to late remitters as the majority of remitting mothers remitted before 3 months.

Our findings are also similar to those reported by Garber et al. (2009), who showed that improvement in parents' depressive symptoms predicted changes in children's depressive symptoms over 2 years. Of note, the findings in children in the Garber study were on the same symptom measures (CDI) as this study, and were also partially explained by improvements in parenting behavior. In the Garber study the measure of parental behavior was supportiveness and acceptance of the child. Neither the STAR*D study nor the Garber study examined the effect of parental relapse. However, Garber et al. (2009) showed that subsequent increases in parental depression were associated with similar changes in offspring. Finally, a randomized clinical treatment study of adolescents at risk for depression because of a previous history of depression found treatment less effective in preventing onset of their illness in the adolescents, if a parent was currently depressed when the adolescent's treatment began (Garber et al. 2009; Beardslee et al. 2013).

\section{Limitations}

There are limitations to this study. The data are observational. Treatment assignment was randomized for the first 3 months but not between 3 and 9 months, so that we cannot draw any conclusions about the effects of treatment. Inherent in the observational design is 
potential selection bias or hidden confounds. The sample of children when divided by mother's remission status is small. We did not have direct observation of mother/child interactions. Future studies may benefit from their inclusion. Finally, we did not assess maternal personality disorders, which may have affected outcome.

\section{Clinical implications}

Strong linkages between maternal depression and youth symptoms highlight the potential clinical benefits of coordinating the mental health care of parents and their children (Weissman \& Olfson, 2009). Recent efforts to develop targeted personalized treatment with biomarkers may help the speed of parental clinical remission. Directly targeting parental skills might also accelerate the impact of maternal remission on children, as has been suggested for parents with alcohol problems (Lam et al. 2008). Outcomes for depressed adults, especially if they are parents, also need to be broadened from clinical symptoms and remission to include social and parental functioning to understand and monitor the effects of maternal depression on the children (De Silvia et al. 2013). How to recruit and maintain depressed mothers into any treatment for themselves, especially if they are poor, will require better access and novel methods of delivery through primary and collaborative care as the US health care system evolves (Simon et al. 2009).

\section{Supplementary Material}

Refer to Web version on PubMed Central for supplementary material.

\section{Acknowledgments}

This study was funded by the following grants: MH082255 Parental Remission for Depression and Child Psychopathology (M.M.W.); and MH076961-01A2 (J.W.S.); MH077285-01A2 (P.B.). L.A.B. is supported by a Canadian Institutes of Health Research (CIHR) Canada Graduate Scholarship Doctoral Award.

\section{Declaration of Interest}

M.M.W. has received funding from the National Institute of Mental Health (NIMH), the National Institute on Drug Abuse (NIDA), the National Alliance for Research on Schizophrenia and Depression (NARSAD), the Sackler Foundation, and the Templeton Foundation; and receives royalties from Oxford University Press, Perseus Press, the American Psychiatric Association Press, and MultiHealth Systems. J.W.S. consulted with Biostrategies, Precision Resources and Scientific Consulting, has received honorariums from Shire Pharmaceuticals, and has received grant funding, honoraria for participation in advisory boards and/or speaking engagements from Forest, Lundbeck and Valeant.

\section{References}

Batten LA, Hernandez M, Pilowsky DJ, Stewart JW, Blier P, Flament MF, Poh E, Wickramaratne P, Weissman MM. Children of treatment-seeking depressed mothers: a comparison with the sequenced treatment alternatives to relieve depression (STAR*D) Child Study. Journal of the American Academy of Child and Adolescent Psychiatry. 2012; 51:1185-1196. [PubMed: 23101744]

Beardslee WR, Brent DA, Weersing VR, Clarke GN, Porta G, Hollon SD, Gladstone TRG, Gallop R, Lynch FL, Iyengar S, DeBar L, Garber J. Prevention of depression in at-risk adolescents: longerterm effects. Journal of the American Medical Association Psychiatry. 2013; 70:1161-1170. [PubMed: 24005242]

Beardslee WR, Gladstone TR, O'Connor EE. Transmission and prevention of mood disorders among children of affectively ill parents: a review. Journal of the American Academy of Child and Adolescent Psychiatry. 2011; 50:1098-1109. [PubMed: 22023998] 
Berensky RA, Talcott JA, Weeks JC. Binary data with two non-nested sources of clustering: an analysis of physician recommendations for early prostate cancer treatment. Biostatistics. 2000; 1:219-230. [PubMed: 12933521]

Bird HR, Shaffer D, Fisher P, Gould MS, Canino G, Rubio-Stipec M. The Columbia Impairment Scale (CIS): pilot findings on a measure of global impairment for children and adolescents. International Journal of Methods in Psychiatric Research. 1993; 3:167-176.

Brotman, LM.; Kamboukos, D.; Theise, R. Symptom-specific measures for disorders usually first diagnosed in infancy, childhood or adolescence. In: Rush, AJ.; First, MB.; Blacker, D., editors. Handbook of Psychiatric Measures. 2nd edn.. Washington, DC: American Psychiatric Press; 2008. p. 333-335.

De Silva MJ, Cooper S, Lishi H, Li L, Lund C, Patel V. Effect of psychosocial interventions on social functioning in depression and schizophrenia: meta-analysis. British Journal of Psychiatry. 2013; 202:253-260. [PubMed: 23549941]

Endicott J, Cohen J, Nee J, Fleiss J, Sarantakos S. Hamilton Depression Rating Scale. Extracted from Regular and Change Versions of the Schedule for Affective Disorders and Schizophrenia. Archives of General Psychiatry. 1981; 38:98-103. [PubMed: 7458574]

First, MB.; Gibbon, M.; Williams, JBW. Structured Clinical Interview for DSM-IV Axis I Disorders (SCID-1). In: Rush, AJ.; First, MB.; Blacker, D., editors. Handbook of Psychiatric Measures. Washington, DC: American Psychiatric Press; 2008. p. 40-43.

Gameroff MJ, Wickramaratne P, Weissman MM. Testing the Short and Screener versions of the Social Adjustment Scale-Self-report (SAS-SR). International Journal of Methods in Psychiatric Research. 2012; 21:52-65. [PubMed: 22139969]

Garber J, Ciesla JA, McCauley E, Diamond G, Schloredt KA. Remission of depression in parents: links to healthy functioning in their children. Child Development. 2011; 82:226-243. [PubMed: 21291439]

Garber J, Clarke GN, Weersing VR, Beardslee WR, Brent DA, Gladstone TR, DeBar LL, Lynch FL, D'Angelo E, Hollon SD, Shamseddeen W, Iyengar S. Prevention of depression in at-risk adolescents: a randomized controlled trial. Journal of the American Medical Association. 2009; 301:2215-2224. [PubMed: 19491183]

Gunlicks ML, Weissman MM. Change in child psychopathology with improvement in parental depression: a systematic review. Journal of the American Academy of Child and Adolescent Psychiatry. 2008; 47:379-389. [PubMed: 18388766]

Hamilton M. Development of a rating scale for primary depressive illness. British Journal of Social and Clinical Psychology. 1967; 6:278-296. [PubMed: 6080235]

Kaufman J, Birmaher B, Brent D, Rao U, Flynn C, Moreci P, Williamson D, Ryan N. Schedule for Affective Disorders and Schizophrenia for School Age Children Present and Lifetime Version (KSADS-PL): initial reliability and validity data. Journal of the American Academy of Child and Adolescent Psychiatry. 1997; 36:980-988. [PubMed: 9204677]

Kovacs, M. The Children's Depression Inventory Manual. Toronto, ON: MultiHealth Systems; 1992.

Lam WKK, Fals-Stewart W, Kelley ML. Effects of parent skills training with behavioral couples therapy for alcoholism on children: a randomized clinical pilot trial. Addictive Behaviors. 2008; 33:1076-1080. [PubMed: 18485612]

Liang KY, Zeger SL. Longitudinal data analysis using generalized linear models. Biometrika. 1986; 73:13-22.

Lieb R, Isensee B, Hofler M, Pfister H, Wittchen HU. Parental major depression and the risk of depression and other mental disorders in offspring: a prospective-longitudinal community study. Archives of General Psychiatry. 2002; 59:365-374. [PubMed: 11926937]

March, JS. Manual for the Multidimensional Anxiety Scale for Children (MASC). Toronto, ON: MultiHealth Systems; 1997.

March, JS.; Parker, JDA. The Multidimensional Anxiety Scale for Children (MASC). In: Maruish, ME., editor. The Use of Psychological Testing for Treatment Planning and Outcomes Assessment. Mahwah, NJ: Lawrence Erlbaum Associates; 1999. p. 299-322. 
March JS, Parker JDA, Sullivan K, Stallings P, Connors CK. The Multidimensional Anxiety Scale for Children (MASC): factor structure, reliability, and validity. Journal of the American Academy of Child and Adolescent Psychiatry. 1997; 36:554-565. [PubMed: 9100431]

Murphy E, Wickramaratne P, Weissman M. The stability of parental bonding reports: a 20-year follow-up. Journal of Affective Disorders. 2010; 125:307-315. [PubMed: 20138671]

Parker G, Tupling H, Brown LB. A parental bonding instrument. British Journal of Medical Psychology. 1979; 52:1-10.

Pilowsky DJ, Wickramaratne P, Talati A, Tang M, Hughes CW, Garber J, Malloy E, King C, Cerda G, Sood AB, Alpert JE, Trivedi MH. Children of depressed mothers 1 year after the initiation of maternal treatment: findings from the STAR*D-Child Study. American Journal of Psychiatry. 2008; 165:1136-1147. [PubMed: 18558646]

Shaffer D, Gould MS, Brasic J, Ambrosini P, Fisher P, Bird H, Aluwahlia S. A Children's Global Assessment Scale (CGAS). Archives of General Psychiatry. 1983; 40:1228-1231. [PubMed: 6639293]

Simon GE, Ludman EJ, Rutter CM. Incremental benefit and cost of telephone care management and telephone psychotherapy for depression in primary care. Archives of General Psychiatry. 2009; 66:1081-1089. [PubMed: 19805698]

Singer JD. Using SAC PROC Mixed to fit multilevel models, hierarchical models, and individual growth models. Journal of Education and Behavioral Statistics. 1998; 29:323-355.

Stewart JW, McGrath PJ, Blondeau C, Deliyannides DA, Hellerstein D, Norris S, Amat J, Pilowski D, Tessier P, Laberge L, O'Shea D, Chen Y, Withers A, Bergeron R, Blier P. Combination antidepressant therapy for major depressive disorder: speed and probability of remission. Journal of Psychiatric Research. 2013 Published online: 17 December 2013.

Weissman MM, Olfson M. Translating intergenerational research on depression into clinical practice. Journal of the American Medical Association. 2009; 302:2695-2696. [PubMed: 20040558]

Weissman MM, Pilowsky DJ, Wickramaratne PJ, Talati A, Wisniewski SR, Fava M, Hughes CW, Garber J, Malloy E, King CA, Cerda G, Sood AB, Alpert JE, Trivedi MH, Rush AJ. STAR*DChild Team Remissions in maternal depression and child psychopathology: a STAR*D-child report. Journal of the American Medical Association. 2006a; 295:1389-1398. [Erratum in Journal of the American Medical Association (2006) 296, 1234]. [PubMed: 16551710]

Weissman MM, Prusoff BA, Thompson WD, Harding PS, Myers JK. Social adjustment by self-report in a community sample and in psychiatric outpatients. Journal of Nervous and Mental Disease. 1978; 166:317-326. [PubMed: 650195]

Weissman MM, Wickramaratne P, Nomura Y, Warner V, Pilowsky D, Verdeli H. Offspring of depressed parents: 20 years later. American Journal of Psychiatry. 2006b; 163:1001-1008. [PubMed: 16741200]

Wickramaratne P, Gameroff MJ, Pilosky DJ, Hughes CW, Garber J, Malloy E, King C, Cerda G, Sood AB, Alpert JE, Trivedi MH, Fava M, Rush AJ, Wisniewski S, Weissman MM. Children of depressed mothers 1 year after remission of maternal depression: findings from the STAR*D-child study. American Journal of Psychiatry. 2011; 168:593-602. [PubMed: 21406462] 


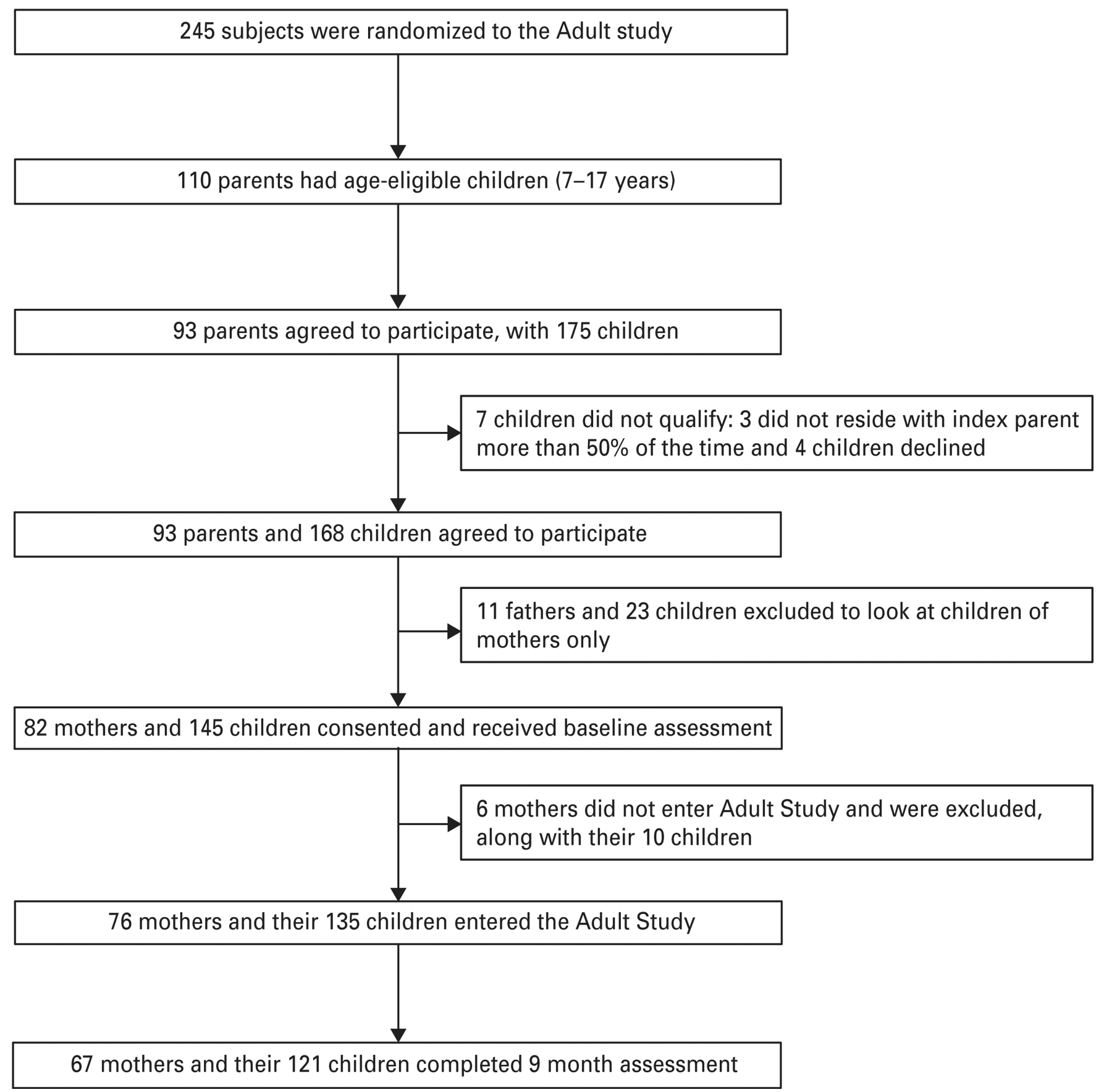

Fig. 1.

Study flow chart. 
Parental Functioning (SAS-SR)

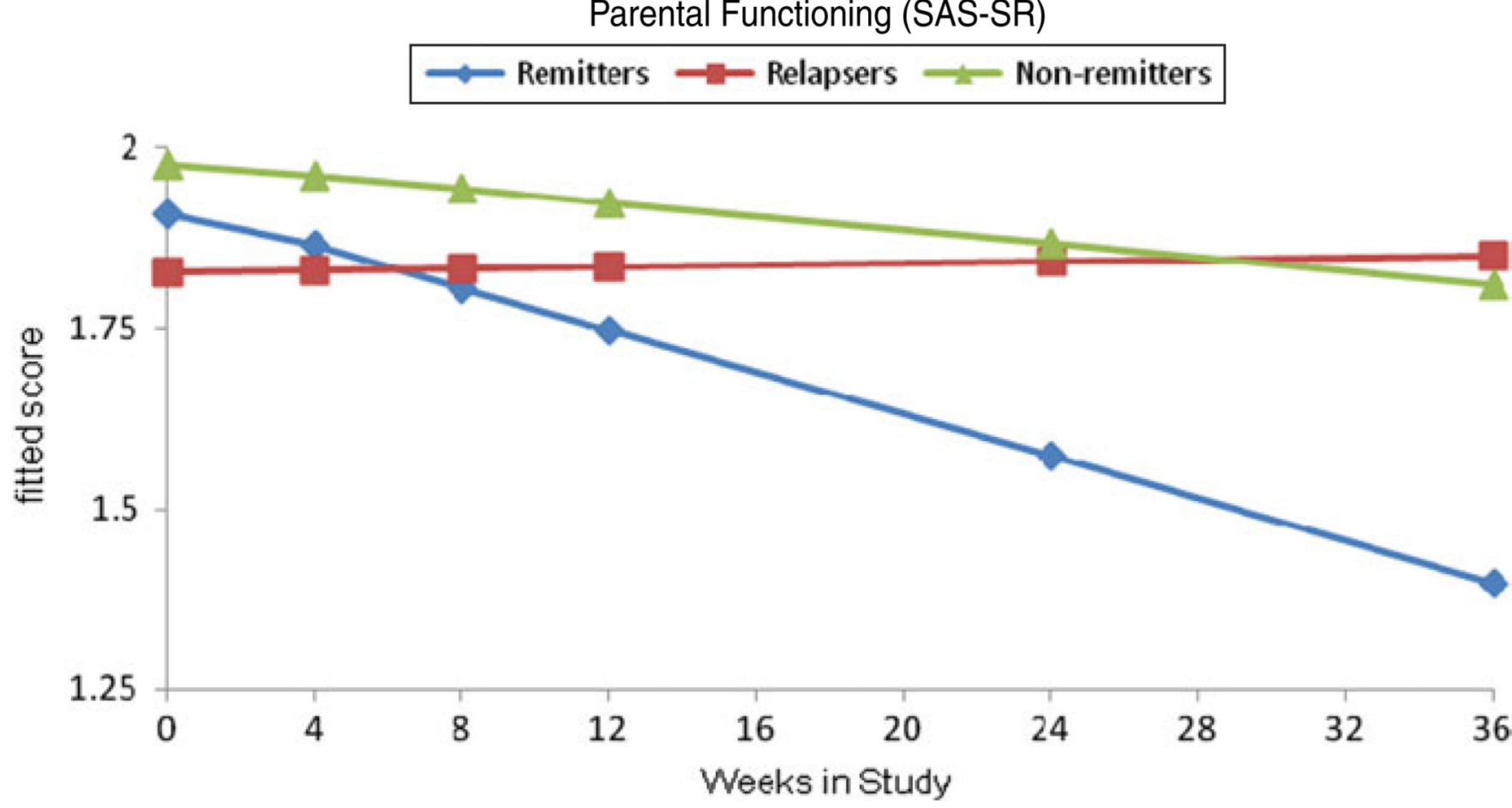

Fig. 2.

The individual $\beta$ values over time by remission status indicate that remitting mothers ( $\beta=$ $-0.015, t=-4.03, p=0.0003)$ improved the most, followed by non-remitting $(\beta=-0.005, t=$ $-0.89, p=0.3802)$ and relapsing mothers $(\beta=0.001, t=0.11, p=0.9112)$. Pairwise comparisons show significant differences between remitting and relapsing mothers $(\beta=-0.015, t=-2.30$, $p=0.0217$ ), and no significant differences between remitting and non-remitting mothers ( $\beta=$ $-0.010, t=-1.62, p=0.1114)$ and between relapsing and non-remitting mothers $(\beta=0.005$, $t=0.71, p=0.4761$ ). (Lower score=less impairment.) 


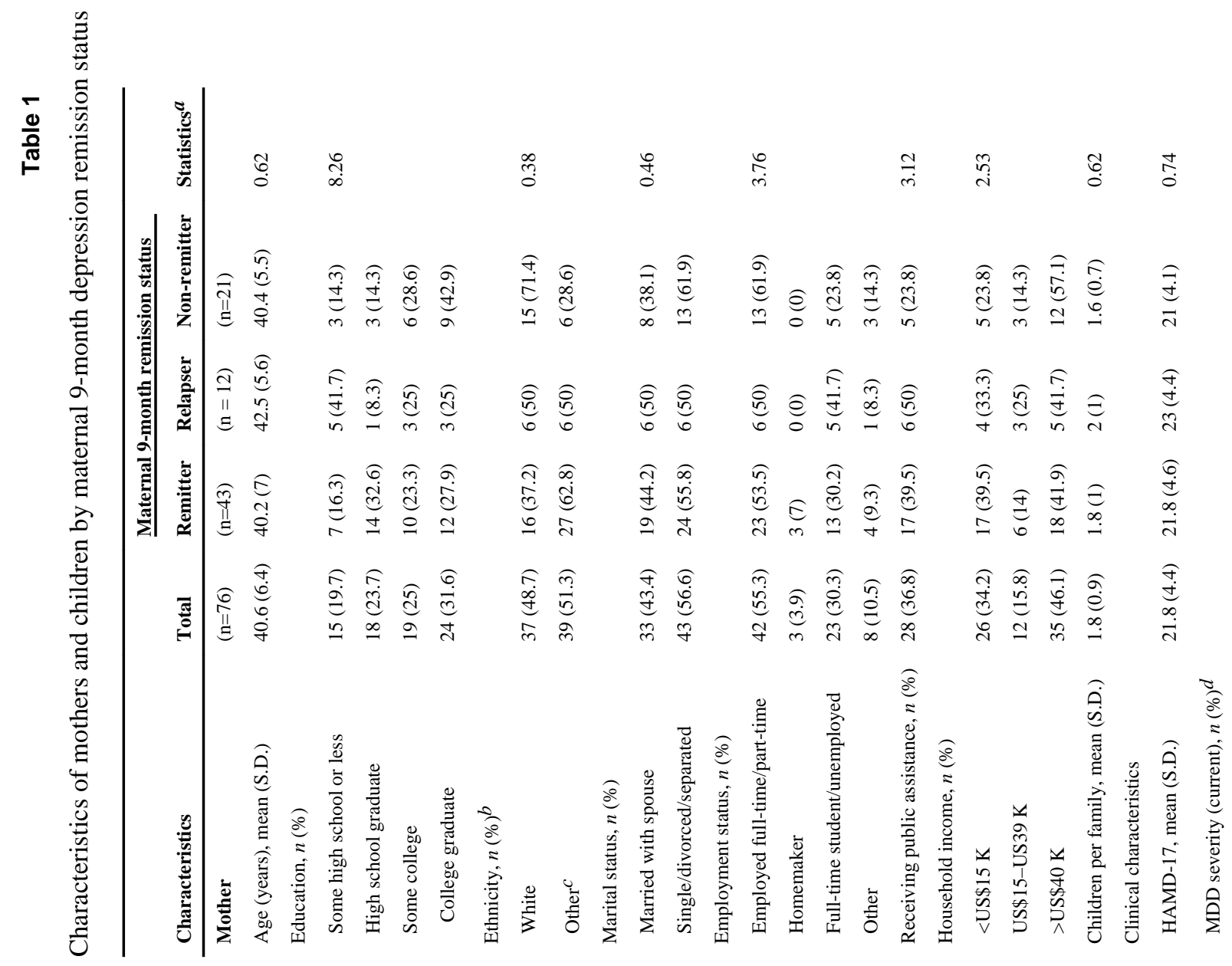




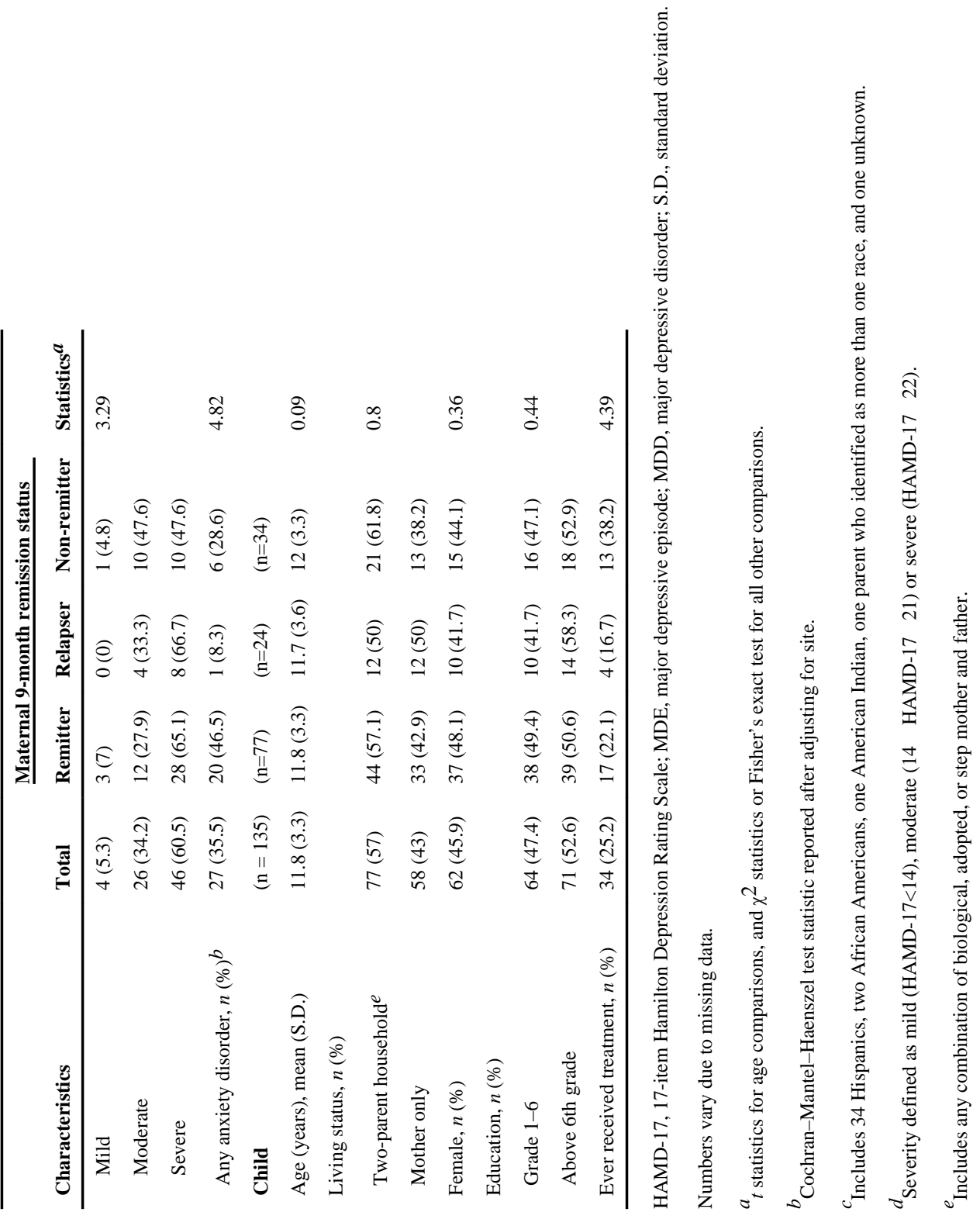




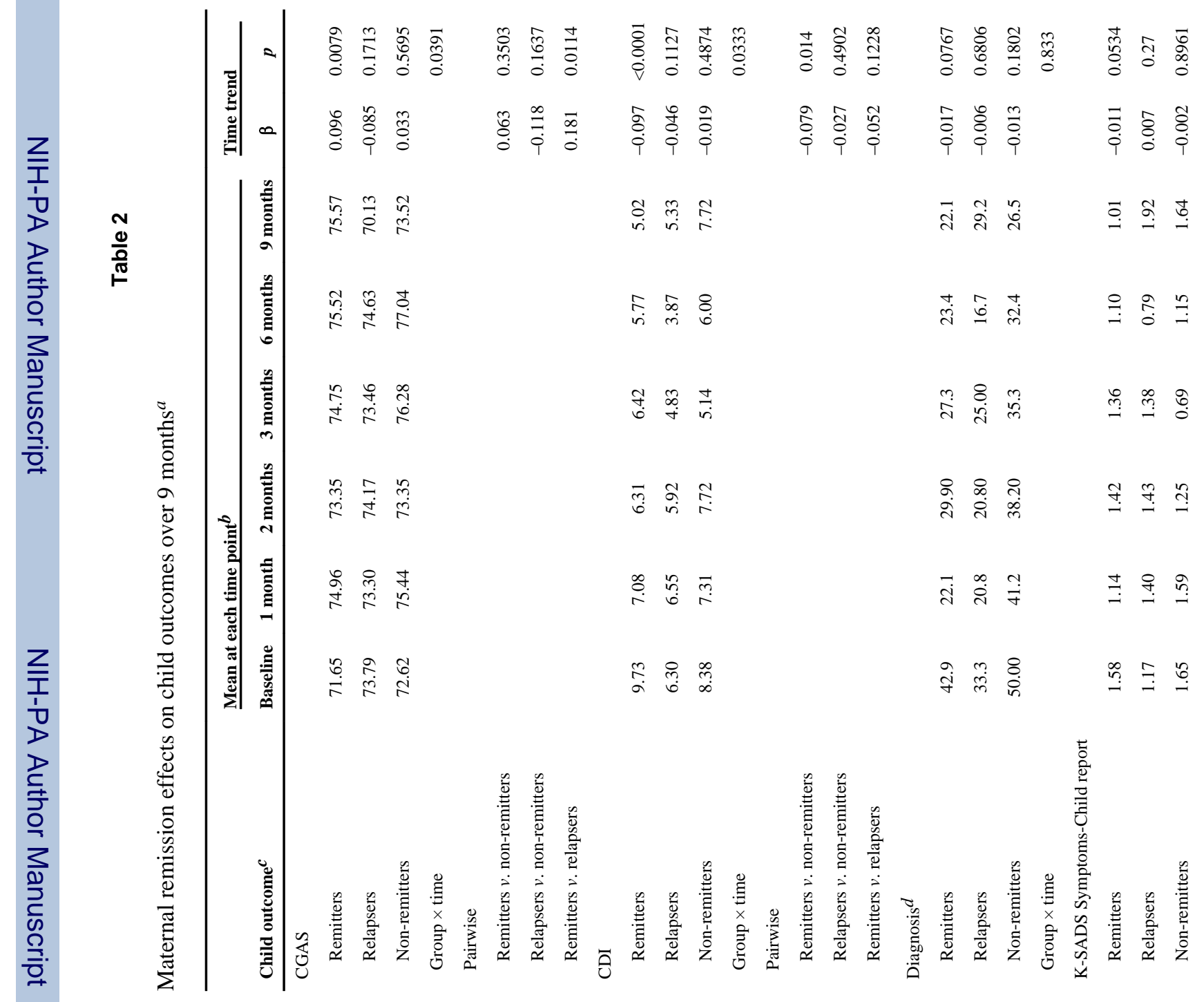




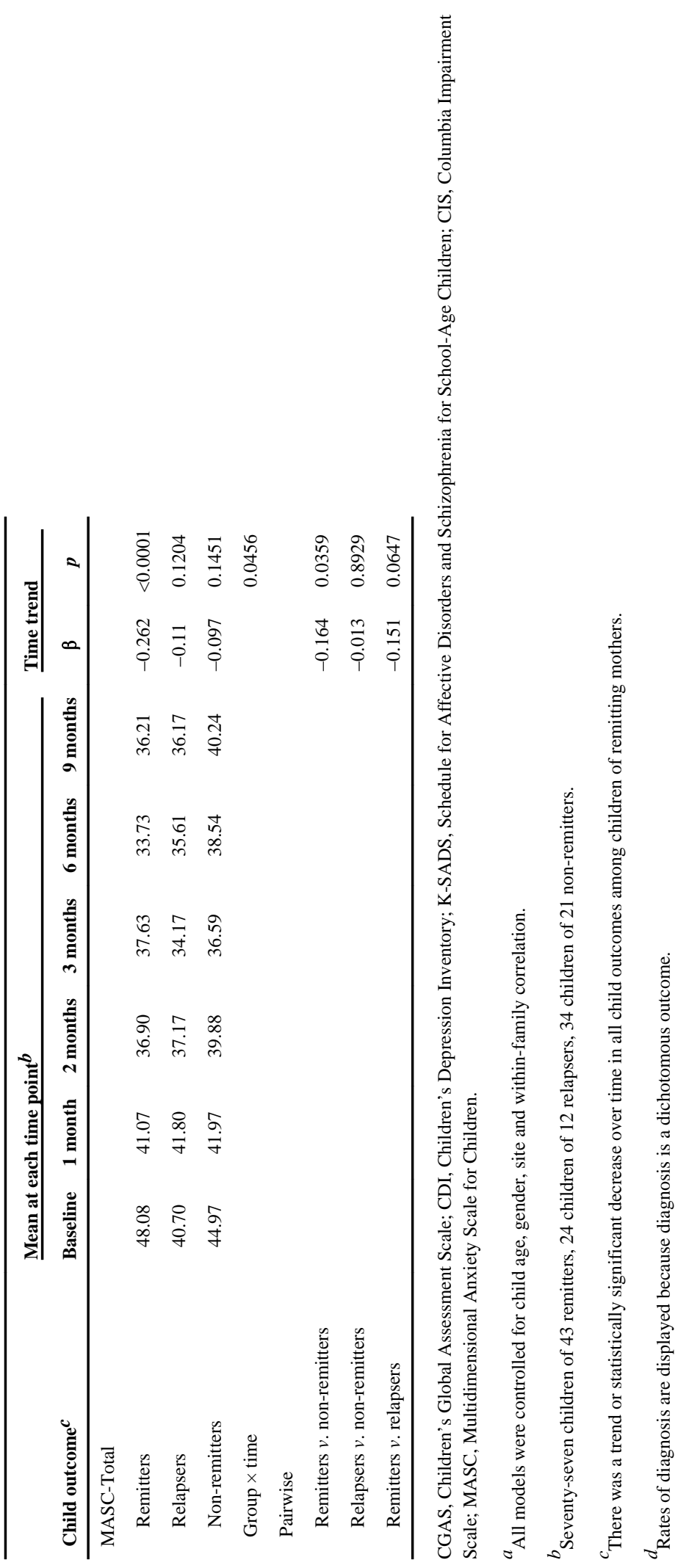




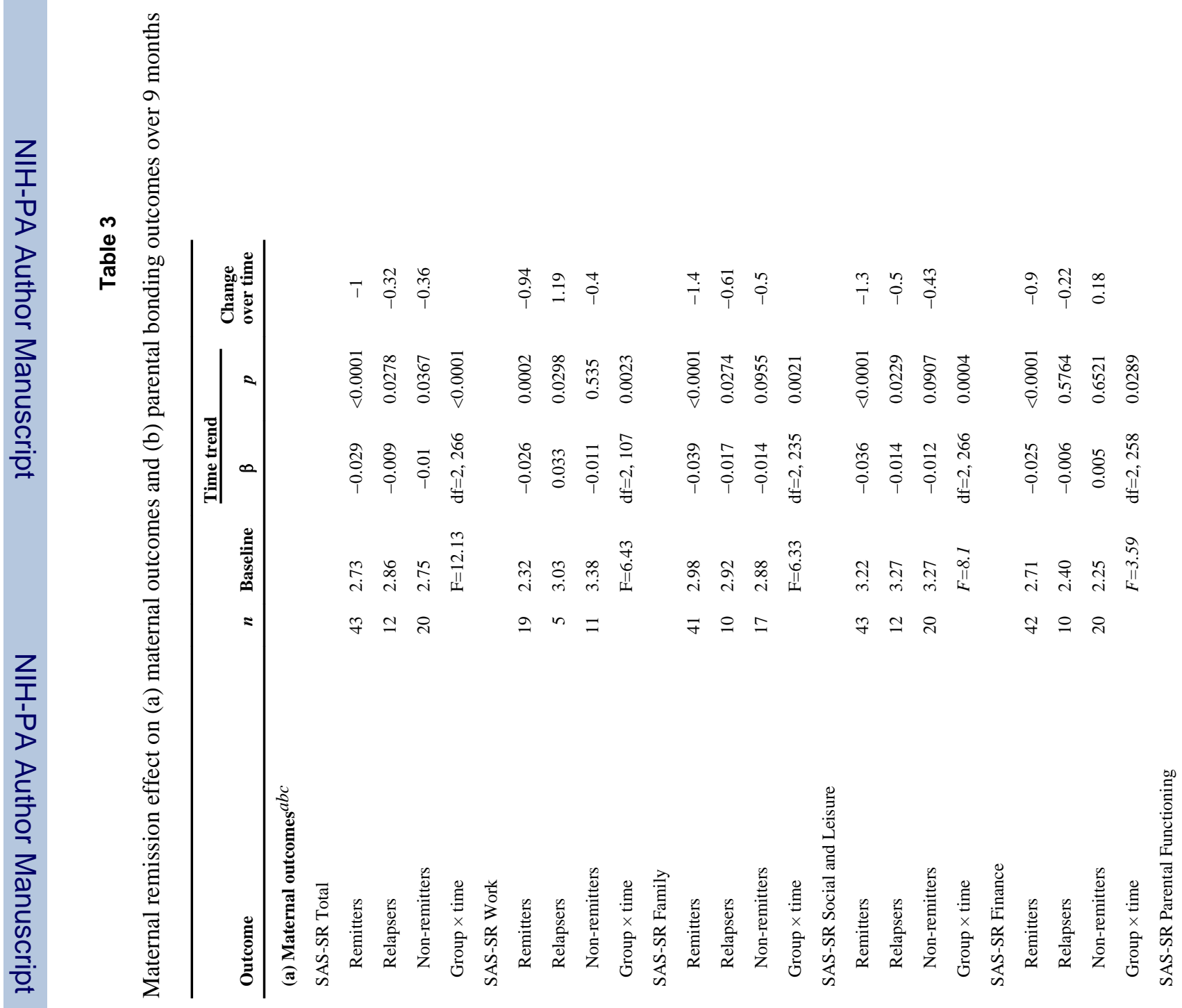




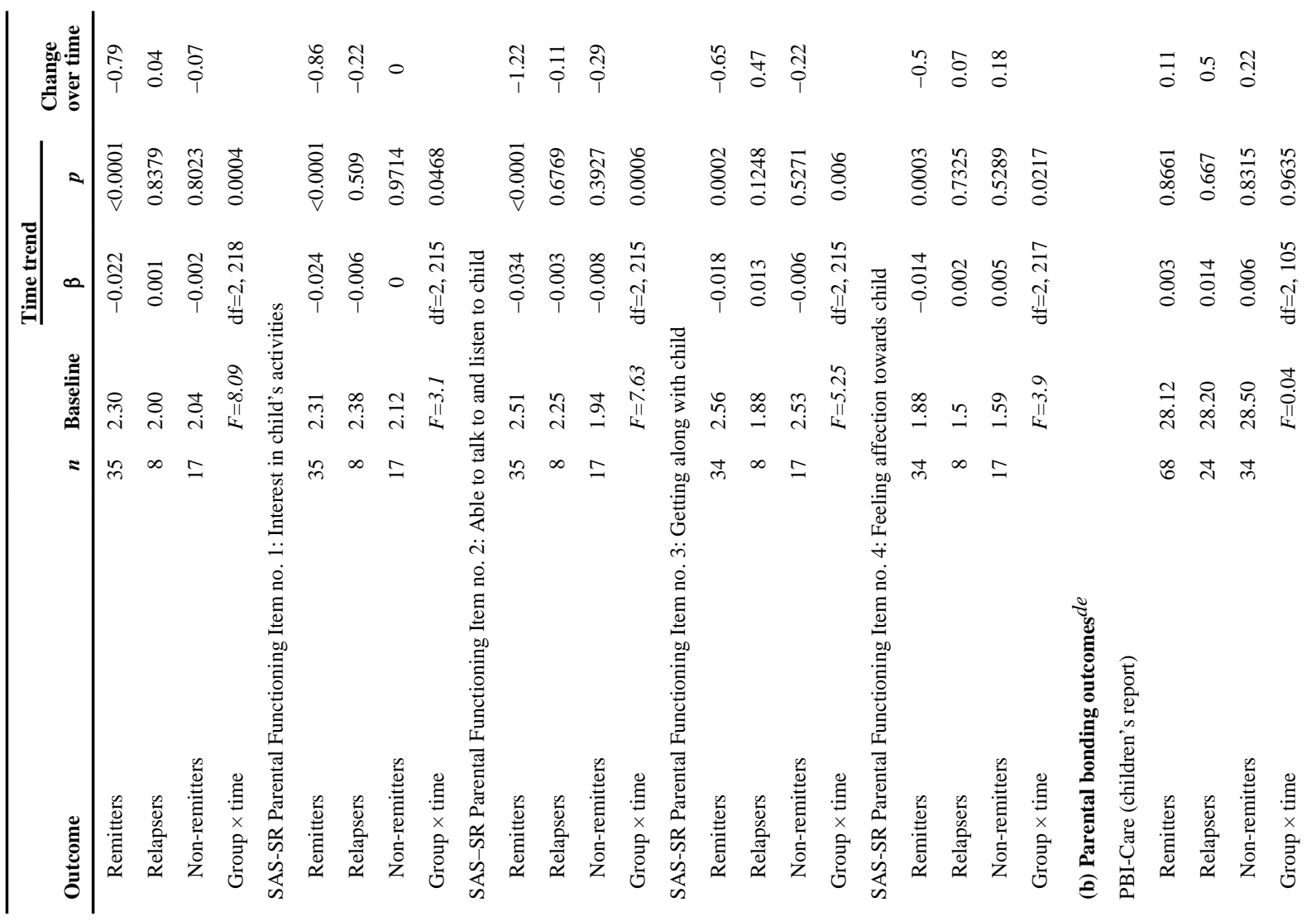




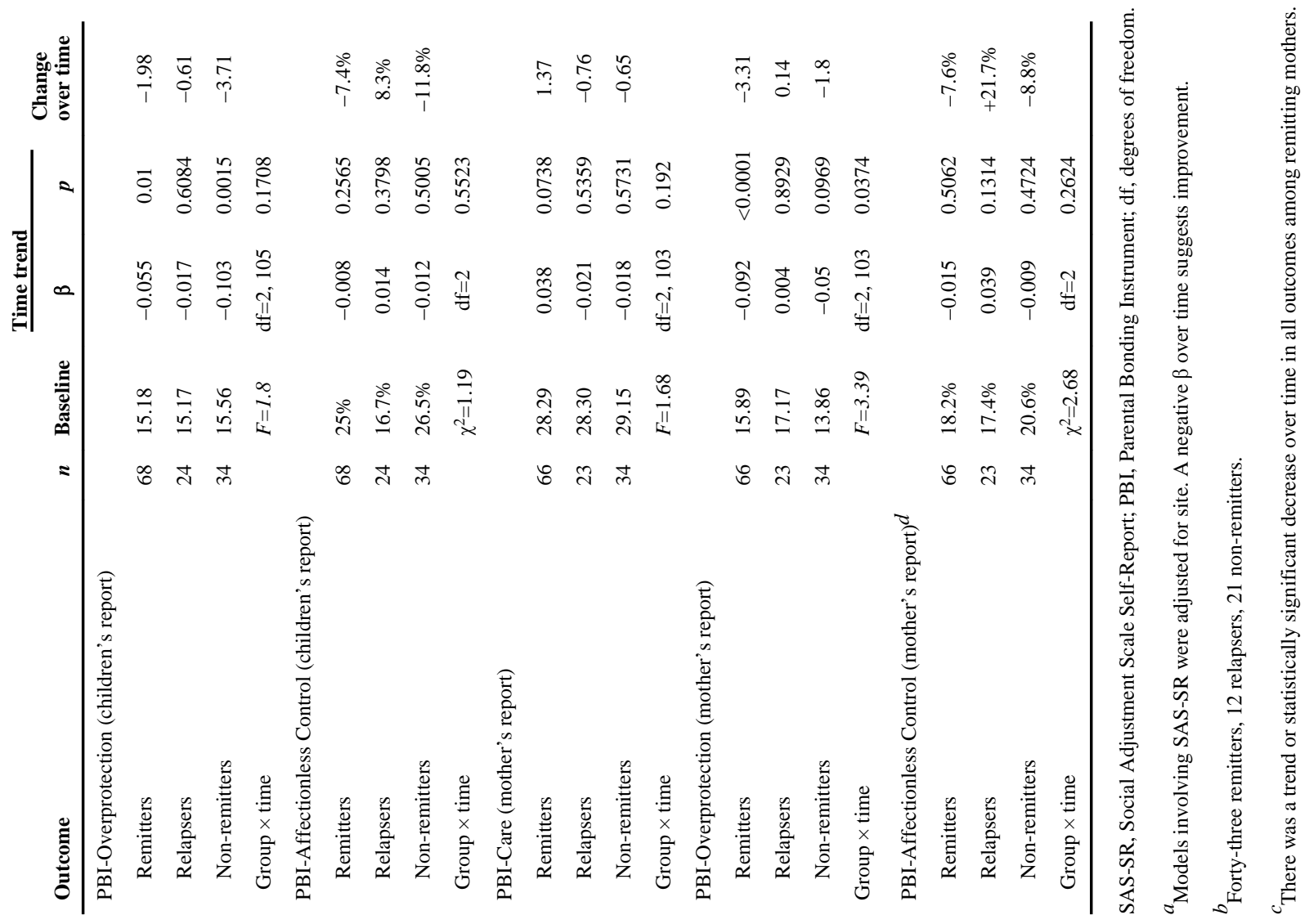


Table 4

Maternal parental functioning and bonding and child outcomes

\begin{tabular}{|c|c|c|c|c|}
\hline & \multicolumn{2}{|c|}{$\underline{\text { Unadjusted model }}$} & \multicolumn{2}{|c|}{$\underline{\text { Adjusted model }}$} \\
\hline & $\beta$ & $p$ value & $\beta$ & $p$ value \\
\hline \multicolumn{5}{|l|}{ SAS-SR Total } \\
\hline \multicolumn{5}{|l|}{ MASC-Social } \\
\hline Week $\times$ remission status & -0.07 & 0.0316 & -0.05 & 0.0921 \\
\hline Parental functioning & & & 0.73 & 0.0208 \\
\hline \multicolumn{5}{|l|}{ MASC-Total } \\
\hline Week $\times$ remission status & -0.17 & 0.0356 & -0.13 & 0.1098 \\
\hline Parental functioning & & & 1.94 & 0.0292 \\
\hline \multicolumn{5}{|l|}{ Parental Functioning Total } \\
\hline \multicolumn{5}{|l|}{ MASC-Social } \\
\hline Week $\times$ remission status & -0.07 & 0.0316 & -0.05 & 0.0954 \\
\hline Parental functioning & & & 0.88 & 0.0011 \\
\hline \multicolumn{5}{|l|}{ MASC-Total } \\
\hline Week $\times$ remission status & -0.17 & 0.0356 & -0.13 & 0.1071 \\
\hline Parental functioning & & & 2.17 & 0.0017 \\
\hline \multicolumn{5}{|l|}{ Parental Functioning Item no. 2} \\
\hline \multicolumn{5}{|l|}{$\mathrm{CDI}$} \\
\hline Week $\times$ remission status & -0.08 & 0.0213 & -0.06 & 0.0952 \\
\hline Parental functioning & & & -0.30 & 0.4616 \\
\hline Parental functioning $\times$ remission status & & & 0.96 & 0.038 \\
\hline \multicolumn{5}{|l|}{ MASC-Social } \\
\hline Week $\times$ remission status & -0.07 & 0.0316 & -0.05 & 0.128 \\
\hline Parental functioning & & & 0.65 & 0.0028 \\
\hline \multicolumn{5}{|l|}{ MASC-Total } \\
\hline Week $\times$ remission status & -0.17 & 0.0356 & -0.13 & 0.1199 \\
\hline Parental functioning & & & 1.40 & 0.0115 \\
\hline \multicolumn{5}{|l|}{ PBI-Overprotection (mother's report) } \\
\hline \multicolumn{5}{|l|}{ MASC-Social } \\
\hline Week $\times$ remission status & -0.06 & 0.0998 & -0.05 & 0.1268 \\
\hline PBI-Overprotection & & & 0.11 & 0.0617 \\
\hline
\end{tabular}

SAS-SR, Social Adjustment Scale Self-Report; MASC, Multidimensional Anxiety Scale for Children; CDI, Children's Depression Inventory; PBI, Parental Bonding Instrument.

${ }^{a}$ Added parental functioning/bonding.

All analyses were controlled for child-centered age and gender, site and within-family correlation. All models were restricted to remitters and nonremitters. 